\title{
Electron Beam Welding of 2099-T83 Aluminium-lithium Alloy Thick Plates
}

\author{
Jozef Bárta ${ }^{1}$, Beáta Šimeková ${ }^{1, *}$, Milan Marônek ${ }^{1}$, and Mária Dománková \\ ${ }^{1}$ Slovak University of Technology in Bratislava, Faculty of Materials Science and Technology in Trnava, Institute of Production \\ Technologies, Slovakia \\ ${ }^{2}$ Slovak University of Technology in Bratislava, Faculty of Materials Science and Technology in Trnava, Institute of Materials \\ Science, Slovakia
}

\begin{abstract}
The paper deals with the welding of AW 2099-T83 aluminium lithium alloy being used for construction of lower wing stringers. The thickness of AW 2099-T83 aluminium lithium alloy was $25.4 \mathrm{~mm}$. Electron beam welding with the accelerating voltage of $55 \mathrm{kV}$ was used for production of welded joints. Welded joints were inspected by computer tomography, macroscopic and microscopic analysis, tensile strength test and microhardness measurement. Welded joints exhibited good weld joint formation, typical to electron beam welding. Weld metal was structure was dendritic formed by $\alpha$ solid solution. Decrease of microhardness was observed mainly in the centre of weld metal due to dissolution of precipitates. The fracture occurred in the weld metal during tensile strength test. Further research will focus on post-heat treatment of welded joints in order to improve mechanical properties of weld metal.
\end{abstract}

\section{Introduction}

In comparison to other aluminium alloys, the $\mathrm{Al}-\mathrm{Li}$ hardenable aluminium alloys offer higher elastic modulus, lower density, higher specific strength and higher tolerance to damage.

The application of structural components made of $\mathrm{Al}-\mathrm{Li}$ alloys plays a key-role in the aerospace industry in order to reduce the weight, increase the payload and improve the fuel efficiency of aircraft [1].

The light alloy component production is very often related to the operation of joining. The standard welding methods such as e.g. Gas Tungsten Arc Welding (GTAW), are characterized by relatively high thermal input, so that the material being welded is significantly heat-affected during welding. This leads to the degradation of structural and mechanical properties of the joints of Al-Li alloys.

Mostly observed defects of welded joints produced by fusion welding processes are hot cracking, porosity and decrease of mechanical properties. However, the knowledge base related to weldability of aluminium lithium alloys is still narrow.

A possible solution to the problems with fusion weldability is the application of solid state welding methods, such as Friction Stir Welding (FSW) [2], but unfortunately this method can't be always implemented. In order to minimize effect of fusion welding on final welded joint properties, the methods with low heat input, i.e. laser and electron-beam welding are preferred. The welded joints fabricated by the mentioned methods exhibit a very narrow HAZ and small deformations.

Information on welding by concentrated energy sources is rather rare. The welding of 2196 and 2198 alloys by $\mathrm{CO} 2$ laser received some world-wide publicity. The trend is the utilization of Al-Li alloy in the production of fillet welds, which are used to join the panels of the aircraft fuselage. In order to eliminate deterioration of the mechanical properties of weld joints during laser welding, it was necessary to ensure sufficient stirring [3]. Further data on laser welding concern the use of fibre laser for welding 2060 alloy with an Al-Mg-based filler material. Microhardness in the weld metal dropped to almost half the hardness of the parent material. Tensile strength of the weld joint achieved approximately $63 \%$ of the parent material strength. All fractures occurred in the weld metal [4]. The welding of Al-Li alloy 5A90 without filler metal by Nd:YAG laser received some publicity. Similarly documented was the decrease in mechanical properties due to reducing the amount of precipitates in the weld metal [5].

As for electron beam welding, only the analysis results regarding the welds fabricated of $\mathrm{Al}-\mathrm{Li}$ alloy 8090 have been published. The alloy is considered as an experimental material. It is a precipitation-hardened alloy based of $\mathrm{Al}-\mathrm{Li}-\mathrm{Cu}-\mathrm{Mg}$. Anisotropic structure strongly influences mechanical properties of the alloy 8090. Hot cracking in the weld metal occurs due to the formation of a eutectic mixture with low melting point. The observed decrease of mechanical properties of the weld metal was due to the welding temperature cycle [6].

Corresponding author: beata.simekova@stuba.sk 
The objective of this paper was to evaluate the possibilities of joining the 2099-T83 aluminium-lithium alloy by electron beam welding.

\section{Methods}

The material used within the experiment was AW 2099T83 aluminium alloy with the thickness of $25.4 \mathrm{~mm}$. Typical chemical composition of this alloy is provided in Table 1.

Table 1. Typical chemical composition of AW 2099-T83 alloy.

\begin{tabular}{|l|l|l|l|}
\hline Element & Weight $\%$ & Element & Weight $\%$ \\
\hline $\mathrm{Cu}$ & $2,4-3,0$ & $\mathrm{Ti}$ & $0,10 \mathrm{max}$ \\
\hline $\mathrm{Li}$ & $1,6-2,0$ & $\mathrm{Fe}$ & $0,07 \mathrm{max}$ \\
\hline $\mathrm{Zn}$ & $0,4-1,0$ & $\mathrm{Si}$ & $0,05 \max$ \\
\hline $\mathrm{Mg}$ & $0,10-0,50$ & $\mathrm{Be}$ & $0,0001 \max$ \\
\hline $\mathrm{Mn}$ & $0,10-0,50$ & Other & $0,15 \max$ \\
\hline $\mathrm{Zr}$ & $0,05-0,12$ & $\mathrm{Al}$ & bal \\
\hline
\end{tabular}

Typical mechanical properties of the material provided by manufacturer are shown in Table 2.

Table 2. Typical mechanical properties of AW 2099-T83 alloy.

\begin{tabular}{|l|l|}
\hline Tensile strength $\mathrm{Rm}[\mathrm{MPa}]$ & 560 \\
\hline Yield strength $\mathrm{Rp}_{0.2}[\mathrm{MPa}]$ & 510 \\
\hline Ductility A [\%] & 4 \\
\hline
\end{tabular}

In order to keep heat input as low as possible and to provide minimum width of heat affected zone, the electron beam welding (EBW) was applied. The parameters of EBW machine are provided in Table 3. The EBW device used for the experiment is shown in Figure 1.

Table 3. Basic parameters of EBW machine.

\begin{tabular}{|l|l|}
\hline Max. output power $[\mathrm{kW}]$ & 30 \\
\hline Operating pressure $[\mathrm{Pa}]$ & $2.10^{-2}$ \\
\hline Chamber volume $\left[\mathrm{m}^{3}\right]$ & 5.6 \\
\hline Max. accelerating voltage $[\mathrm{kV}]$ & $\max .60$ \\
\hline
\end{tabular}

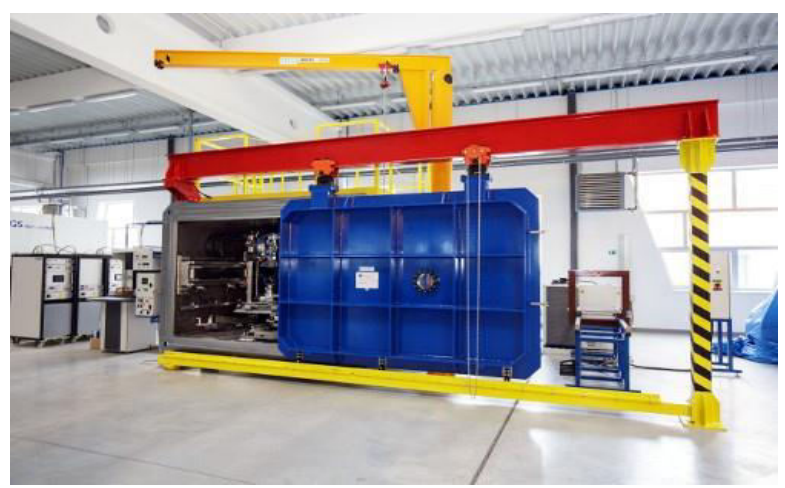

Fig. 1. EBW machine.
Within the experiment the welded joint microstructure was analysed using standard metallography procedure. Samples taken from welded joint were grinded and polished. Keller etchant $(2 \mathrm{ml}$ HF, $3 \mathrm{ml} \mathrm{HCL}, 5 \mathrm{ml} \mathrm{HNO} 3$, and $190 \mathrm{ml} \mathrm{H} 2 \mathrm{O}$ ) was used for etching. Subsequently the microstructure of the welded joint was analysed using optical microscope Neophot 32.

Tensile strength of welded joints was measured according to ISO 5178:2001 standard. Three pieces from each sample were used in order to obtain the average values of tensile strength.

Microhardness of the weld joints was realised using 100 grams load and 5 second indentation time. Microhardness was analysed in base material, in the weld metal adjacent to the weld surface, as well as in the centre and in the root section of welded joint. Moreover, the microhardness was also analysed in line starting from welded joint axis towards the base metal.

\section{Experimet}

The samples were welded in flat position according to ISO 6947. The canon distance from sample surface was $200 \pm 5 \mathrm{~mm}$. Samples were cleaned from grease after the cutting process. Welding parameters are provided in Table 4.

Table 4. Welding parameters.

\begin{tabular}{|l|l|l|l|}
\hline Sample & 1 & 2 & 3 \\
\hline Accelerating Voltage $[\mathrm{kV}]$ & 55 & 55 & 55 \\
\hline Focusing Current $[\mathrm{mA}]$ & 646 & 646 & 646 \\
\hline Welding current $[\mathrm{mA}]$ & 117 & 117 & 117 \\
\hline Welding Speed $[\mathrm{mm} / \mathrm{s}]$ & 15 & 20 & 25 \\
\hline
\end{tabular}

Figure 2 shows the weld surface appearance. The full penetration was observed in all welded joints. No significant spatter was observed. Sample No.1 exhibited irregularities in width of welded joint surface and the biggest weld root reinforcement. The weld width of other two samples was regular. All samples exhibited reinforcement of weld root. Sample No. 3 exhibited also the reinforcement of the welded joint surface.

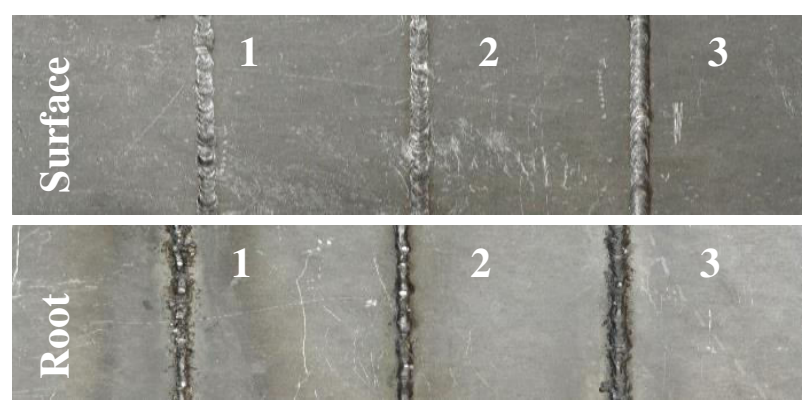

Fig. 2. Welded joints appearance.

Figure 3 documents the macroscopic analysis results. The macroscopy analysis revealed the porosity in 
all welded joints. The weld width was very narrow in all samples, as expected for electron beam welding.
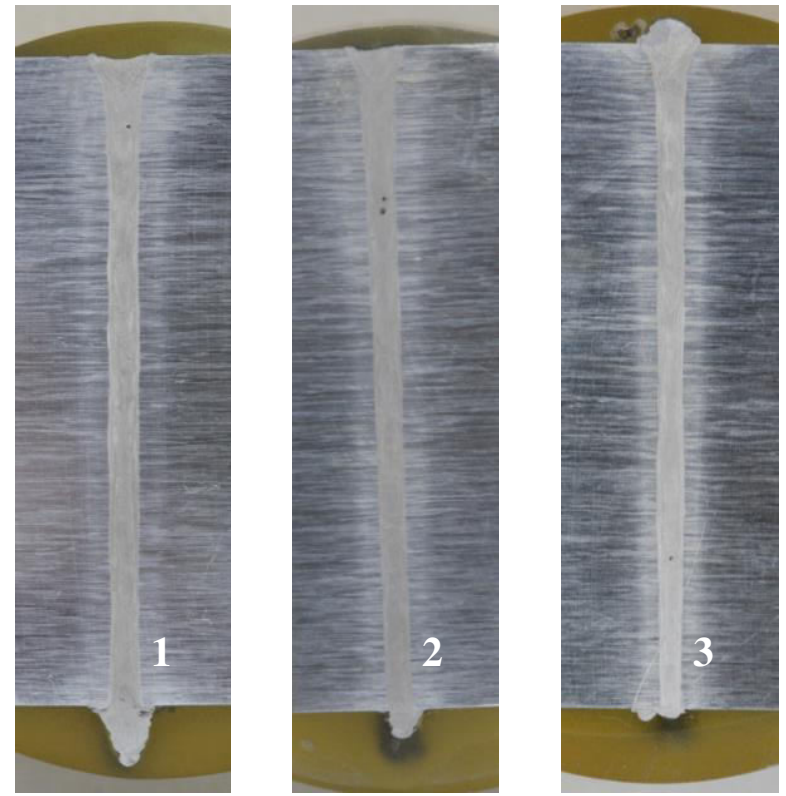

Fig. 3. Cross sections of welded joints.

The maximum size of the observed pore was 283 $\mu \mathrm{m}$. The lowest porosity was observed in sample No. 3 .

The microscopic analysis of base metal shows deformed grains as a consequence of rolling (Figure 4). The black particles represents the precipitates, strengthening the alloy.

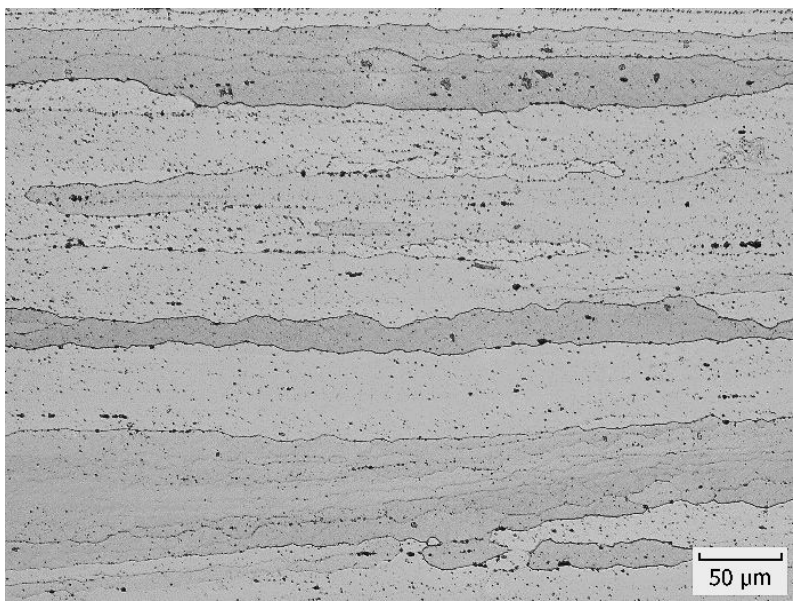

Fig. 4. Microstructure of AW 2099-T83 alloy.

The microstructure of welded joints exhibited small difference in particular areas. Figure 5 documents the microstructure near the surface, in the middle and in the root section of the welded joint. The microstructure in the middle of the weld metal was formed by fine dendritic grains (with size about $10 \mu \mathrm{m}$ ) due to the highest cooling rate. The biggest grains were observed near the weld surface as expected.

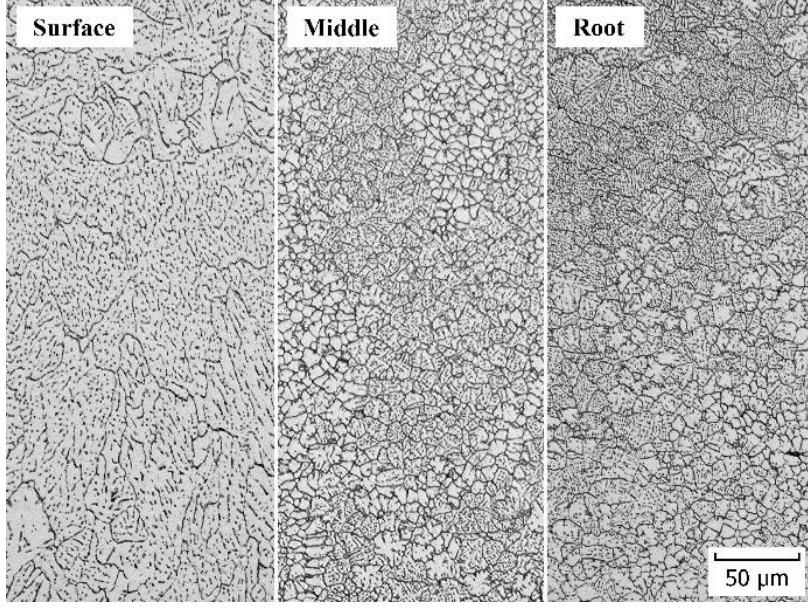

Fig. 5. Microstructure of weld metal.

Figure 6 documents microstructure of the transition zone from weld metal (WM) to base material (BM). The heat affected zone is b0arely visible, however the microhardness measurement confirmed the presence of annealed area next to the weld metal.

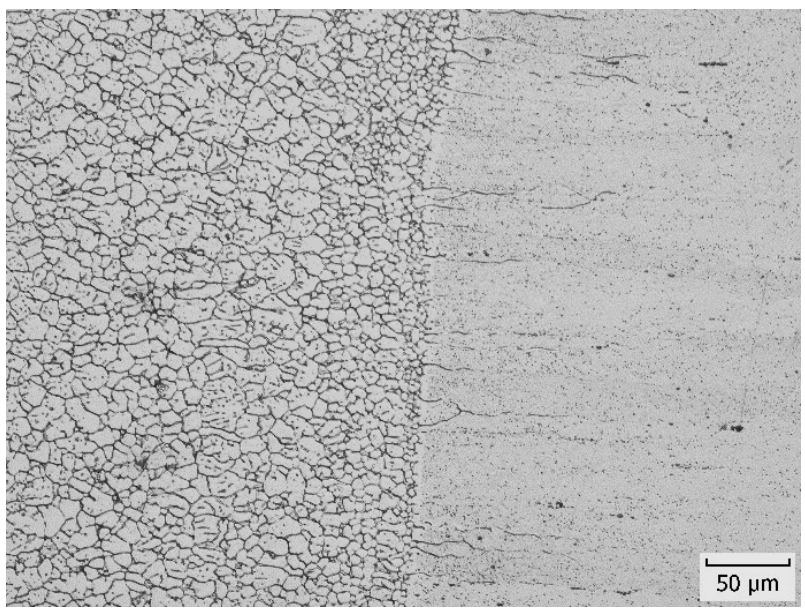

Fig. 6. Microstructure of transition area WM to BM.

The results of tensile strength test showed the average value of $366.43 \mathrm{MPa}$. The measured values were significantly lower in comparison to the base material. The tensile strength of welded joint was only $65.43 \%$ of strength declared by manufacturer (560MPa). Main reasons for this significant decrease are the porosity in weld metal and annealing caused by welding process.

Average microhardness value in weld metal was 79.65 HV0.1 and 173.1 HV0.1 in base material what represents the $53.98 \%$ decrease. The microhardness differences in upper and lower sections of weld metal were insignificant. Reason of microhardness decrease was dissolution of precipitates in the weld metal caused by remelting of the base material. The results also showed that the microhardness of the base material was affected up to $2.6 \mathrm{~mm}$ from welded joint axis (Figure 7). 


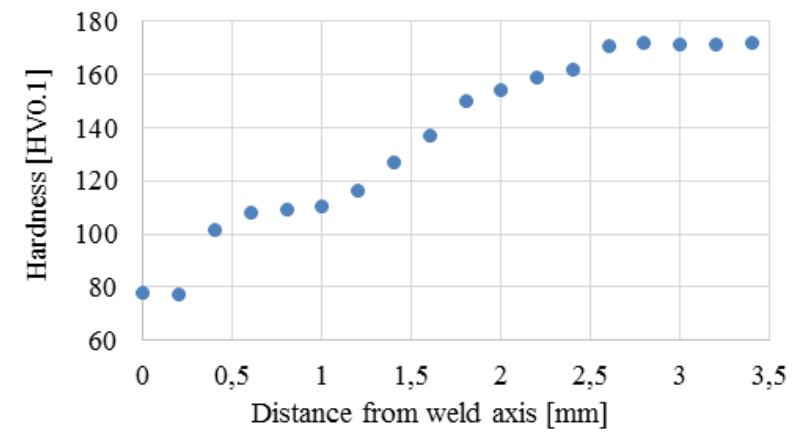

Fig. 7. Results of microhardness measurement.

\section{Conclusion}

The results regarding weldability of AW 2099-T83 aluminium lithium alloy by electron beam welding are promising. Weld metal exhibited dendritic structure having grain size in range from $10 \mu \mathrm{m}$ to $80 \mu \mathrm{m}$ in dependence on its position. As expected, originally hardened base material was annealed in weld metal as well as in distance from weld metal axis up to $2.6 \mathrm{~mm}$. The annealing and porosity of welded joints caused the tensile strength drop to $65.43 \%$.

Best results were achieved in sample No.3. This sample showed lowest porosity, no convexity in welded joint surface and smallest weld root reinforcement.

Further research will be focused on more precise analysis of the porosity using computer tomography and heat treatment to improve the mechanical properties of welded joints.

This work was supported by the Slovak Research and Development Agency under the contract No. APVV-15-0337.

\section{References}

1. Rioja RJ, Liu J. The evolution of Al-Li base products for aerospace and space applications. Metall Mater Trans A 2012;43:3325-37.

2. B. Cai, Z.Q. Zheng, D.Q. He, S.C. Li, H.P. Li: Friction Stir Weld of 2060 Al-Cu-Li Alloy: Microstructure and Mechanical Properties. In Journal of Alloys and Compounds 2015, Vol. 649, s. 19-27.

3. J. Enz, S. Riekehr, V. Ventzke, N. Kashaev: Influence of the Local Chemical Composition on the Mechanical Properties of Laser Beam Welded Al-Li Alloys. In Physics Procedia 2012, Vol. 39, s. 51-58.

4. X. Zhang,W. Yang, R. Xiao: Microstructure and Mechanical Properties of Laser Beam Welded Al-Li Alloy 2060 with Al-Mg Filler Wire. In Materials and Design 2015, Vol. 88, s. 446-450.

5. L. Cui, X. Li, D. He, L. Chen, S. Gong: Effect of Nd:YAG Laser Welding on Microstructure and Hardness of an Al-Li Based Alloy. In Materials Characterization 2012, Vol. 71, p. 95-102.
6. A. Ravindra, E.S. Dwarakadasa, T.S. Srivatsan, C. Ramanath, K.V.V. Iyengar: Electron Beam Weld Microstructures and Properties of AluminiumLithium Alloy 8090. In Journal of Materials Science 1993, Vol. 28, s. 3173-3182. 